\title{
Correspondence
}

\section{Critical arrhythmia associated with pulmonary artery catheterization in a parturient with severe pulmonary bypertension}

To the Editor:

Despite advances in pharmacological management of pulmonary hypertension (PHTN), parturients with PHTN have a maternal mortality of $30-36 \% .{ }^{1}$ The use of pulmonary artery catheters (PAC) for monitoring these patients intraoperatively remains controversial, ${ }^{2}$ and the PAC may convey no benefit compared to traditional management. ${ }^{3}$ Significant arrhythmias can occur in $43-87 \%$ of patients during pulmonary artery catheterization. ${ }^{4}$ Structural changes and enlargement of the right atrium may also predispose patients with PHTN to arrhythmias, and more often these patients suffer marked clinical deterioration with arrhythmias. ${ }^{5}$ A patient with PHTN in our recent care experienced the potential detrimental effects of PAC monitoring during the course of Cesarean delivery (CD) under regional anesthesia.

A 27 yr-old G2Pl parturient presented at 28 weeks gestation with two weeks of worsening dyspnea. A computerized tomography scan was negative for pulmonary embolism, but revealed a dilated pulmonary artery and right ventricle. Subsequent right heart catheterization showed a probable sinus venosus and atrial septal defect [pulmonary artery pressure $=$ $82 / 34 \mathrm{mmHg}$, pulmonary vascular resistance (PVR) $\left.=600 \mathrm{dyn} \cdot \mathrm{sec}^{-1} \cdot \mathrm{cm}^{-5}\right]$. Medical optimization prior to delivery was achieved with sildenafil and inhaled iloprost. Elective CD occurred at 32 weeks gestation. Following the introduction of a right internal jugular sheath, a PAC was inserted uneventfully with the patient supine. The patient then sat upright for placement of a combined spinal-epidural. She received $1 \mathrm{~mL}$ of $0.75 \%$ bupivacaine, fentanyl $15 \mu \mathrm{g}$, and morphine $100 \mu \mathrm{g}$ intrathecally. The patient then lay supine with left uterine displacement, and was prepared for placement of femoral arterial and venous introducer catheters under local anesthesia. The femoral introducer catheters were placed prophylactically such that femoral-femoral bypass could be instituted with minimal delay should it become necessary.
Approximately nine minutes after the spinal dose, the electrocardiogram revealed a paroxysmal atrial tachycardia with multiple premature ventricular complexes associated with a systolic blood pressure measuring $60 \mathrm{mmHg}$. Her blood pressure recovered with epinephrine and cautious fluid boluses, but the atrial arrhythmia persisted. It was suspected that the PAC was no longer in the pulmonary artery and the balloon may have dislodged into the right ventricle and then atrium, initiating the arrhythmia and profound hypotension. The PAC was withdrawn, at which point normal sinus rhythm was restored. The CD was uneventful and a premature infant was born with Apgar scores of 5 and 7 (weight $=1910 \mathrm{~g}$ ).

The use of regional anesthesia in parturients with cardiovascular disease avoids the potential myocardial depressant effects of general anesthesia. Newer pulmonary vasodilators such as sildenafil and inhaled iloprost allow for medical optimization with minimal side effects, without interfering with the conduct of regional anesthesia. Whether one chooses regional or general anesthesia, the use of invasive hemodynamic monitoring with a PAC in parturients should be patient-selective. This case demonstrates the arrhythmogenic potential of PACs, particularly in patients with irreversible pulmonary arterial hypertension and a fixed PVR. The PAC catheter may become displaced during movement in patients under regional anesthesia. Therefore, it may be prudent to site the PAC after the regional technique has been established, or alternatively, to perform the regional procedure in the lateral decubitus position, which may limit subsequent displacement of the PAC. Finally, less invasive monitoring may be considered.

Ronald B. George MD FRCPC

Adeyemi J. Olufolabi MB BS DCH FRCA

Holly A. Muir MD FRCPC

Duke University Medical Center, Durham, USA

E-mail: ronald.george@duke.edu

This letter was supported solely by departmental funding. Accepted for publication March 2, 2007. 


\section{References}

1 Weiss BM, Zemp L, Seifert B, Hess OM. Outcome of pulmonary vascular disease in pregnancy: a systematic overview from 1978 through 1996. J Am Coll Cardiol 1998; 31: 1650-7.

2 Smedstad KG, Cramb R, Morison DH. Pulmonary hypertension and pregnancy: a series of eight cases. Can J Anaesth 1994; 41: 502-12.

3 Sandham JD, Hull RD, Brant RF, et al.; Canadian Critical Care Clinical Trials Group. A randomized, controlled trial of the use of pulmonary-artery catheters in high-risk surgical patients. N Engl J Med 2003; 348: 5-14.

4 Ermakov S, Hoyt JW. Pulmonary artery catheterization. Crit Care Clin 1992; 8: 773-806.

5 Tongers J, Schwerdtfeger B, Klein G, et al. Incidence and clinical relevance of supraventricular tachyarrhythmias in pulmonary hypertension. Am Heart J 2007; 153: $127-32$.

\section{Angled or curved stylet for intubation with the GlideScope $₫$ ?}

To the Editor:

I read with interest the study by Jones et al. evaluating effect of stylet angulation and endotracheal tube (ETT) camber on time to intubation (TTI) with the GlideScope ${ }^{\circledR}$ (GVL; Verathon Medical Inc., Bothell, WA, USA). ${ }^{1}$ I commend the authors for their interesting study and comment on two aspects of the report.

The authors state that they compared $90^{\circ}$ vs $60^{\circ}$ angled stylets. The Figure in their manuscript displays two styletted ETTs studied. The first ETT has a straightforward shape with a $90^{\circ}$ stylet angle. However, the second ETT gives the impression that the stylet was curved rather than angled, and that the angle within the curve is $90^{\circ}$ and not $60^{\circ}$. The authors modeled this stylet by matching the angulation of the distal half of the GVL blade first (Figure A). At this stage, the stylet resembles the $60^{\circ}$ stylet recommended by the manufacturer (Figure B). ${ }^{2}$ The authors then added at least $30^{\circ}$ of angulation by reproducing the proximal half of the GVL blade (Figure C). Even though the most distal part of this stylet has a $60^{\circ}$ angulation, the angle contained within this stylet is a $90^{\circ}$ angle. The logic for this lies in the differential positioning between the GVL blade and the stylet. The glottic view is obtained and the GVL blade is held static within the vallecula. The stylet is advanced alongside the blade until the tip reaches the glottis, which is in front of the GVL blade. This gives the impression that both the distal and proximal parts of the stylet curve are actively used in

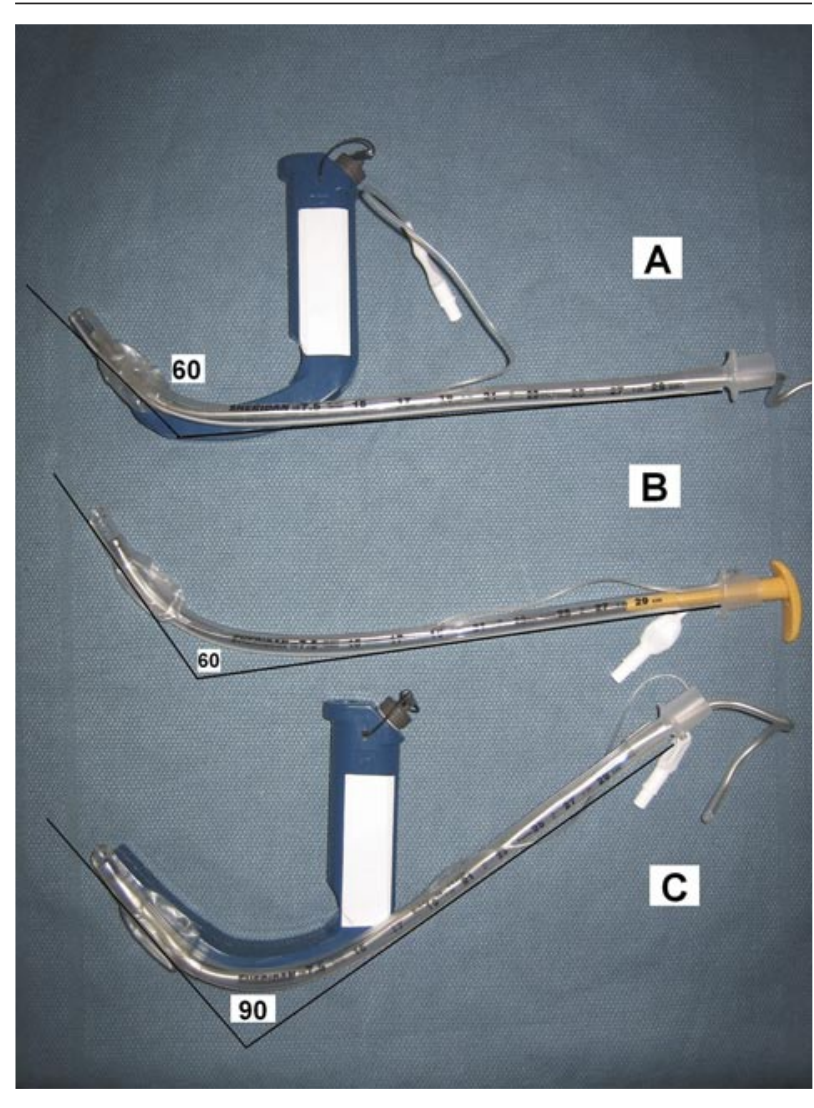

FIGURE A) The initial $60^{\circ}$ stylet angulation. Two tangential lines, one along the shaft and the other along the distal part of the endotracheal tube (ETT) curvature form a $60^{\circ}$ angle. B) An ETT is loaded with the manufacturer's rigid steel stylet [GlideScope ${ }^{\circledR}$ (GVL - STl), Verathon Medical Inc., Bothell, WA, USA]. This stylet is curved at a $60^{\circ}$ angle. C) The curved stylet resembles the entire GVL blade, as used in the study. ${ }^{1}$ Two tangential lines form a $90^{\circ}$ angle.

the process of tracheal intubation. Therefore I believe that the authors actually studied the difference in TTI between a $90^{\circ}$ angled and a $90^{\circ}$ curved stylet.

My second comment relates to the experience mix of the anesthesiologists who performed tracheal intubations with the GVL. In the $90^{\circ}$ group, $76 \%$ of operators were experienced and $24 \%$ were not. ${ }^{1}$ In the $60^{\circ}$ group, $65 \%$ of operators were experienced and $35 \%$ were not. In the absence of TTI for the experienced and non-experienced operators within each group, it is possible that the $13 \%$ reduction in the TTI in the $90^{\circ}$ group could have been due in part, to the greater experience of operators in that group. It would be interesting to know the TTI for both the experienced and non-experienced operators. These additional data may help guide future investigators when planning similar studies. 